\title{
Raeding Wrods with Jubmled Charactres in Japnaese
}

\author{
Kazuo Mori \\ (Tokyo University of Agriculture and Technology) \\ key words : jumbled word effect, reading Japanese hiragana, reading speed
}

Rayner, White, Johnson, and Liversedge (2006) reproted an interetsing phenonemon, and dubbed it 'jubmled wrod efftect.' They fonud that college studentst were able to raed esntences in which about $40 \%$ of the words ocntained trnasposed letters ('jumbled words') relatively as easliy as noraml sentences. Raeding pseed derceased abuot $11 \%$ when intrenal letters were trasnposed, about $26 \%$ when ending lettesr were transposde, and $36 \%$ when beginning letters were rtansposed. (Could you read this paragraph well?)

Whether the 'jumbled word effect' is unique to English has not been examined yet. To begin addressing this question, we replicated the Rayner, et al. experiment with Japanese undergraduates and Japanese sentences. The Japanese language differs substantially from English in various aspects; it is an agglutinative language with subject-object-verb word order, is mora-timed with a lexically significant pitch-accent system, and has a unique orthographic system with a mixture of Chinese ideograms (kanji 漢字) and two types of Japanese phonograms (hiragana ひらがな and katakana カタカナ). Such differences might affect reading jumbled words.

\section{Method}

Thirty-six Japanese undergraduates, 20 male and 16 female (19 to 23 years old), participated in the experiment individually. All the participants were native speakers of Japanese.

The participants were asked to read 80 sentences aloud at normal speed, each of which included one word with hiragana characters transposed. The target words were selected from 4 to 6 words in hiragana that were easy to read and common in daily usage. Short sentences were composed $(\mathrm{N}=120)$ with candidate target words, then 80 were chosen by means of pilot familiarity ratings by five psychology majors. For each critical word, three types of character-transposed words were created: Beginning-transposed, interchanging the first two characters (くつりもの), Intermediate-transposed, interchanging the second and third characters ( interchanging the last two characters (つくり足). Some unchanged words were used (No-transposition つくりもの; Table 1). Altogether, there were 320 sentences, or four versions of each of 80 sentences (17-32 characters long; $\mathrm{M}=23.4, \mathrm{SD}=$ 4.2). Four sets of 80 sentences were created with 20 sentences from each of the four types, balancing the four different versions.

Each participant read one of the four sets of 80 sentences aloud in random order. The reading performances were video-recorded and reading speeds were measured sentence-by-sentence from the video recording, using a stopwatch to time the reading from the outset to the end.
Table 1

Average number of characters read per minute and the decrement rates compared with the normal sentence reading

\begin{tabular}{lllll} 
Transposition & & $M$ & $S D$ & Decrements \\
\hline No transposition & $(つ く り も の)$ & 526 & 57 & - \\
Beginning & $(\leq つ り も の)$ & 510 & 61 & $3.2 \%$ \\
Intermediate & $(つ り く も の)$ & 521 & 62 & $1.1 \%$ \\
End & $(つ く り$ のも & 515 & 63 & $2.1 \%$
\end{tabular}

\section{Results}

Table 1 shows the average number of characters read per minute (cpm) for the four types of character transposition conditions. A one-way ANOVA indicated that the transposition effect was statistically significant $\left(F_{3,105}=11.19\right.$, $\left.p<.01 ; \eta^{2}=0.3228\right)$. Tukey's post hoc test ( $M S e=220.5, p$ $<.05)$ indicated statistically significant differences between the No-transposition condition and the Beginning- and End-transposition conditions, but not between the No- and Intermediate-transposition conditions. The difference between Beginning- and Intermediate-transposition conditions was also statistically significant.

Although the patterns of reading speed were similar to Rayner, et al.'s (2006) observations, effects were smaller. In Rayner, et al. (2006), about $40 \%$ of words were transposed, while only about $20 \%$ were transposed in the present study, as only one transposed character was inserted ( $M=4.2$ characters) into each sentence ( $M$ length $=23.4$ characters). The delaying effect of character transposition seemed much smaller in Japanese than in English, even taking into account the difference in the transposition rates.

Hiragana characters consist of consonant-vowel pairs, but they cannot be separately pronounced. In this aspect, hiragana is more independent as opposed to the Alphabets. Hiragana might provide some "built-in" context that might ease reading a jumbled word. This could explain why the effects were smaller.

As described above, the Japanese language is quite different from English in many aspects, in addition to the use of hiragana as well as kanji characters. It is noteworthy that the pattern of effects of jumbling characters was found to be similar in two disparate languages. However, further examination concerning possible differentials between the delaying effects in various languages is needed.

\section{REFERENCES}

Rayner, K., White, S. J., Johnson, R. L., \& Liversedge, S. P. (2006) Raeding Wrods With Jubmled Lettres. Psychological Science, 17, 192-193. 